
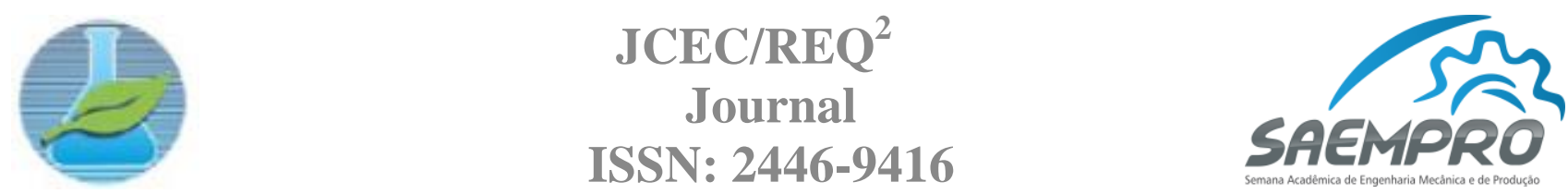

\author{
"EU, A INDÚSTRIA E O MUNDO" \\ 08 a 11 de novembro de 2016 no campus Viçosa da UFV \\ Departamento de Engenharia de Produção e Mecânica - DEP \\ Universidade Federal de Viçosa - UFV
}

\title{
IMPANTAÇÃO DA GESTÃO POR PROCESSOS EM INSTUIÇÃO FINALTRÓPICA EM VIÇOSA-MG
}

\author{
Denise da Silva Barbosa, Gabriel Nunes Fonseca Lima e Silva \\ Universidade Federal de Viçosa, Departamento de Engenharia de Produção e Mecânica \\ Ph. Rolfs s/n - 36570-000 - Viçosa - MG \\ densie.s.barbosa@ufv.br, gabriel.n.silva@ufv.br
}

\section{INTRODUÇÃO}

É possível definir gestão por processos como uma metodologia para avaliação do desempenho dos processos chaves de uma organização, a fim de analisa-los e melhora-los de forma contínua. Consideramos processos chaves aqueles dotados de atividades específicas para transformação de determinadas entradas em saídas específicas de maneira contínua, mas serem dotados também de grande importância para promoção da satisfação dos clientes (Carvalho; Paladini, 2012). Para implantação dessa metodologia, é necessário executar o mapeamento dos processos, conhecendo-os e forma profunda, a fim de descobrir possíveis pontos de melhoria até então desconhecidos.

As vantagens dessa metodologia são inúmeras, sendo possível citar a integração dos processos da organização na busca por um resultado positivo para a organização como um todo, orientação das saídas da organização para atendimento das necessidades dos clientes, desenvolvimento de senso de colaboração entre os colaboradores e melhoria contínua pela revisão dos processos (Paim et al., 2009).

A aplicação de ferramentas de gestão não se restringe às organizações cuja principal meta seja o retorno de forma monetária, visto que organizações sem fins lucrativos, reconhecidas pelos benefícios que trazem a sociedade, também necessitam de ferramentas que garantam o bom funcionamento dos seus processos, garantindo a entrega de valor de bem-estar comunitário que promovem. Porém, as ferramentas devem ser adaptadas para o cotidiano dessas organizações integrantes do terceiro setor (Teixeira, 2006).

Com o propósito de estudar a aplicação de ferramentas de gestão por processos em uma instituição do terceiro setor, foi escolhida uma organização da cidade de Viçosa. Esta apresenta mais de 30 anos de funcionamento, visto que através de quatro programas para atendimento de crianças e adolescentes em situação de vulnerabilidade social, é capaz de impactar mais de 300 famílias diretamente. A equipe de projeto é integrada por quatro membros que recebem suporte da ONG Engenheiros Sem Fronteiras.

Inicialmente, o interesse por esta instituição se deu por esta apresentar visível retrabalho e sobreposição de tarefas entre os colaboradores, divisão pouco clara de tarefas entre departamentos e dependência de pessoas e não de cargos, vista a ausência de documentação de processos e gestão do conhecimento. Desta forma, neste resumo será apresentada a metodologia escolhida para implantação e os resultados obtidos até o momento, visto que o projeto ainda está em implantação.

\section{OBJETIVO}

O objetivo deste resumo consiste na exposição na metodologia seguida até o momento para implantação de ferramentas referentes à gestão por processos em uma instituição filantrópica 
localizada na cidade de Viçosa, MG. O processo de implantação dessas ferramentas ainda está em andamento, de forma que serão discutidos os resultados parciais de tal implantação.

\section{METODOLOGIA}

A natureza técnica deste trabalho permite que sejam descritos a seguir os procedimentos metodológicos adotados para implantação da gestão por processos na instituição, adaptando as ferramentas da área ao seu contexto de aplicação. Tais atividades podem ser descritas em três macro fases, conforme exposto a seguir:

\subsection{Preparação da infraestrutura necessária à gestão por processos}

Tal macro fase abordará as atividades de determinar os objetivos de aplicação das ferramentas de gestão a fim de adequá-las para o contexto da instituição de aplicação, além do delineamento das etapas e entregas principais da implantação. Serão executadas ainda ações de sensibilização de todos os colaboradores da organização sobre os objetivos a serem alcançados e os benefícios esperados do projeto.

\subsection{Diagnóstico da instituição}

Aqui estão reunidas as atividades referentes à análise da organização, identificando suas principais demandas, através de entrevistas com os funcionários para iniciar mapeamento dos processos. Além disso, será realizada a validação por parte da diretoria executiva do cronograma e das atividades a serem desempenhadas pela equipe de projeto. A fim de auxiliar no processo de proposição de melhorias, será realizada uma pesquisa sobre as melhores práticas em assuntos cabíveis à instituição, como estrutura organizacional ótima, técnicas e ferramentas de gestão já empregadas em outras instituições similares e programas estruturados de captação de recursos.

\subsection{Implantação das ferramentas e incorporação à rotina organizacional}

Ocorrerá a elaboração dos Fluxogramas e Procedimentos Operacionais Padrões (POP's) referentes aos processos determinados como chaves para entrega de valor da instituição, além da elaboração de outros documentos auxiliares que se fizerem necessários. Será proposta a adequação de propostas segundo as pesquisas anteriormente realizadas sobre melhores práticas passíveis de implantação. Por fim, há o treinamento dos funcionários quanto aos novos processos $\mathrm{e}$ procedimentos e a utilização da documentação elaborada pela equipe de projeto.

Após o encerramento da implantação, pretende-se realizar duas visitas posteriores para acompanhamento dos resultados do projeto e verificação da efetividade das ferramentas anteriormente propostas.

\section{RESULTADOS}

Após a realização de entrevistas junto aos colaboradores foi possível identificar os processos atribuídos a cada um dos cargos e quais as relações de subordinação existentes entre estes cargos. Dessa forma, foram desenvolvidos o organograma e as descrições de cargo. Apesar de filantrópica, seu organograma é do tipo Horizontal e apresenta grandes semelhanças com qualquer outra organização, apresentando uma Assembleia deliberativa no topo, a Diretoria Executiva e a Diretoria como cargos de alta hierarquia. Além disso, a instituição possui uma Área Administrativa e outra Educacional, relacionada aos programas oferecidos à crianças, adolescentes e mães em situação de vulnerabilidade social.

As descrições de cargos realizadas contêm informações importantes para o bom funcionamento da organização. No documento há uma pequena descrição da importância do cargo, a quem se deve sua subordinação direta, cada atividade exercida por ele e as habilidades e competências exigidas à pessoa que ele o ocupar. Sendo assim, os colaboradores terão definidas 
com clareza as atividades a serem realizadas evitando sobreposição de tarefas ou a não realização de alguma delas por falta de um responsável definido.

Após validação dos colaboradores, os documentos já feitos servirão de base para a definição dos processos-chave, e, a partir desses serão confeccionados os POP's e IT's para padronização das melhores práticas. Por fim, serão deixadas ferramentas de verificação da efetividade dos documentos gerados para posterior análise dos resultados a médio e longo prazo.

\section{CONCLUSÃO}

Espera-se com a conclusão do trabalho que a instituição consiga uma melhora significativa na execução de seus processos, uma carga de trabalho melhor distribuída entre seus colaboradores e um maior controle das atividades e seus resultados gerados. As preocupações dos membros do projeto são relacionadas à aplicabilidade dos documentos gerados à longo prazo, uma vez que a instituição não possui nenhum cargo específico para garantir o cumprimento dos mesmos. Além disso, a rotatividade no local é alta, gerando, muitas vezes, perda de conhecimentos que devem sem documentados, mantendo-os atualizados.

Através do estudo realizado, percebe-se que a gestão por processos é uma metodologia cabível a qualquer tipo de organização, até mesmo filantrópica, onde os processos não são executados com a finalidade de obter lucro. Isso porque através do mapeamento e reconhecimento dos processos pode-se definir quais aqueles que geram mais impacto nos resultados da organização, qualquer seja seu objetivo, e melhorá-los buscando as melhores práticas para os mesmos.

\section{REFERÊNCIAS}

CARVAlHO, M. M.; PALADINI, E. “Gestão da Qualidade: Teoria e Casos". 2 ed. Rio de Janeiro: Elsevier: ABEPRO, 2012, 430p.

TEIXEIRA, M. L. M. “Gestão de ONG's de pequeno e médio porte”. Porto Alegre, RS. UFRS, 2006. Disponível em: https://www.lume.ufrgs.br/bitstream/handle/10183/8821/000589571.pdf?seque nce =1>

PAIM, R.; CARDOSO, V.; CLEMENTE, R.; CAULLIRAUX, H. "Teoria e prática sobre gestão por processos". 1 ed. Bookman, 2009. 